\title{
$\mathfrak{D} \circ \mathfrak{r} \mathfrak{e} d \mathfrak{e}$
}

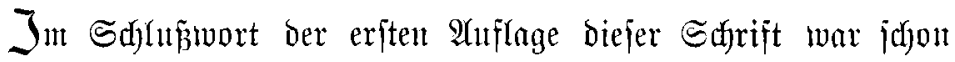

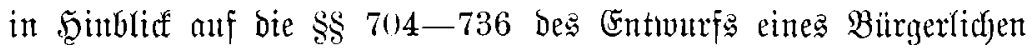

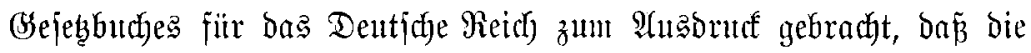

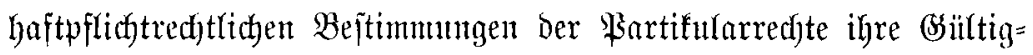
feit verlieren wïrben. Dieje Frognoje hat ficf banf ber energifdyent unto grïndridjen 2 rrbeit ber gejesgebenden Faftoren bejtätigt. (Es

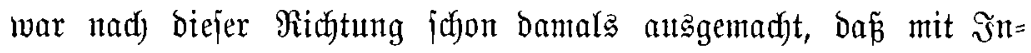
frafttreten Des̃ neuen bürgerlidyen Redfts biejer Teil ber Sdyrift mur

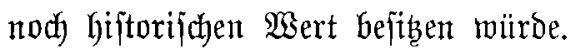

Dagegen wurbe an ber gleidfen Stelfe ber Borausfidyt nady auts=

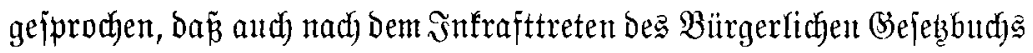

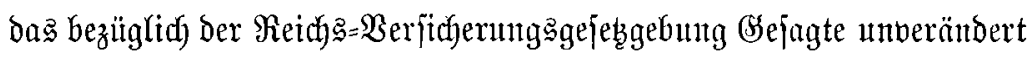

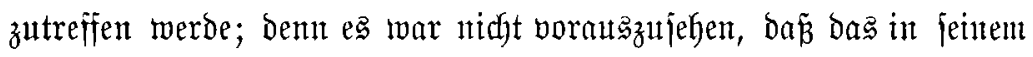

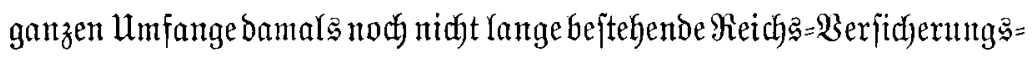
recht gleidffalla eine einja)neidende Umänderung erfahren wïrbe. Uno

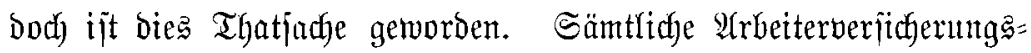

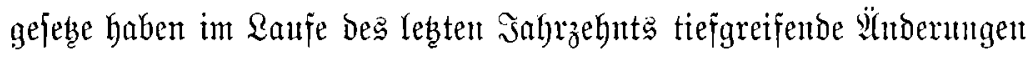
erfahren und netue Bruppen ber Bevölferung wuroen in bent Sreis Der Berfitcherungsgejebe einbezogent.

(5) war baher eine volfftändige Bearbeitung bes nunmehr neuten, einheitlid) geidaffenten Stoffes bringent geboten, um in ber jo

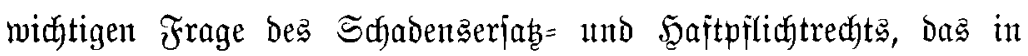
alle Sphären bes mirtidafttidjen und jozialen Rebens einoringt, dent 


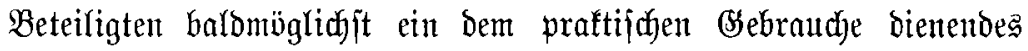
Merf in bie দ̧⿻上丨𣥂 zu geben.

Denn bie Bedeutung biejer gejeţlichen Bejtimmungen, bie nament=

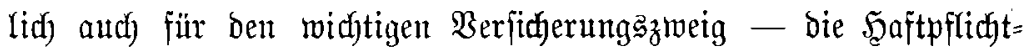
verficjerung - in Betrad)t fommt, foroert ein $\mathfrak{B e r f}$, das ben im

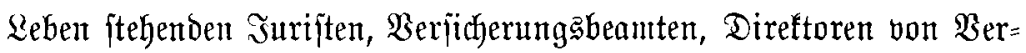

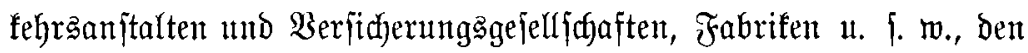
Berwaltungąbeamten, Borftänden Der Berufg̈genofienfdaften 2 c. mit ben Yeitenden Brebanfen auf biefem Rechtsgebiet vertraut madht.

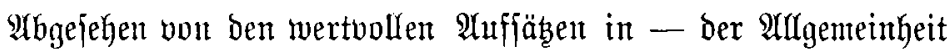

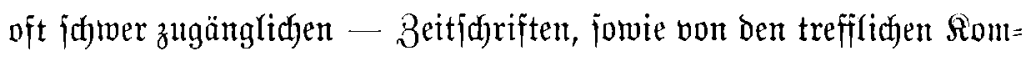
mentaren von $B \mathfrak{l} \mathfrak{n} \mathfrak{x}, \mathfrak{v}$. Staubinger, Sertmann 2 ., hat bie Qittera=

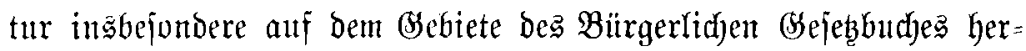

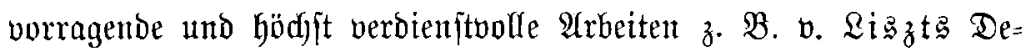

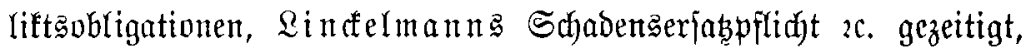

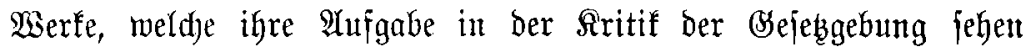

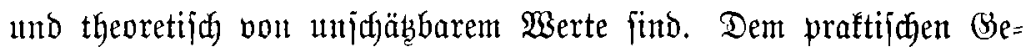
braudbe ftehen fie zu ferne und jie wollen dempelben amfdeinent auth gar nidat bienten, wie ja jhon - um ein rein äußerlidjes Moment zu betonen - aus bent Mangel eines Sadjregifters heroorgehen bürfte.

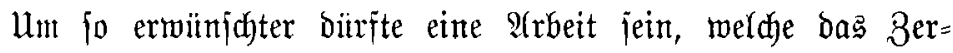
ftreutliegende jammelt, bie Ergebniffe jener Forjum

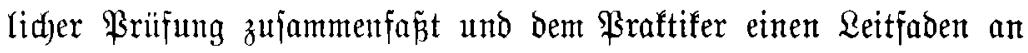

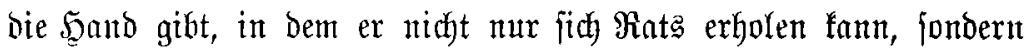
aud) zutr eigenten weiterent Forjautng bei Bearbeitung eines prafti= ¡đuen Falles reidylidyes Material findet. Die Scauptarbeit ift alfer= bings weber vom Bejebgeber noch vom Bearbeiter einer foldyen ipeziellen Frage gethan. Dieje wirb vielmefr von ber Rechtipredyung ïbernommen und ausgebaut werben miiffer. Sie wird zmar gar

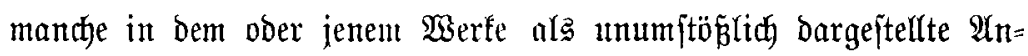
jicht berwerfen; bie Şypotfeje ift aber barum nicht entbehrlich, fie läutert ben bedanfen, indem fie fïh) mit ing befääftigt und forbert 


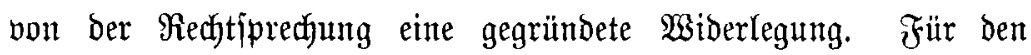
Praftifer genügt ber Şinweis auf bas Bejtehen einer Siontroverje

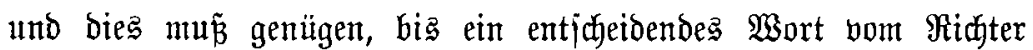
geiprodien ijt.

Uน

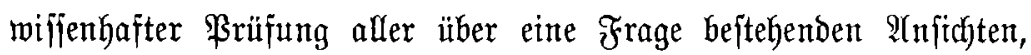

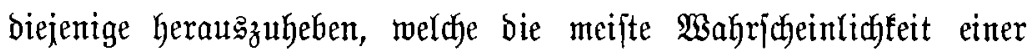
Sanftionierung burd) bie Beridfte für judf hat; bie Bertreter ber anderen Meinungen jïnd nad Mlöglicffeit genannt, und swtroe aus

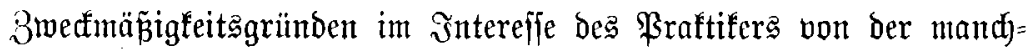

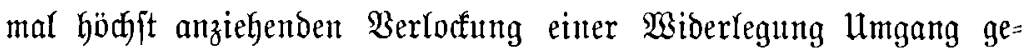
nommen.

An biejer Stelle bagegen joll auf eine durd die Sirtif gegebente Anregung eingegangett werben, wonad) bas Bebautern ausgefprodjen

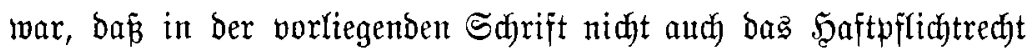
in Bezug auf Sachichaben behandelt worden jei.

Die Sdyrift will - wie aus dem Titel zu erjeben - bie $\mathfrak{B e}=$

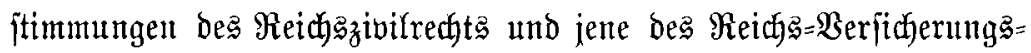

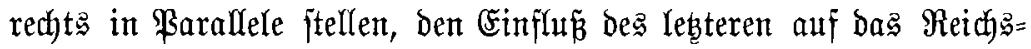

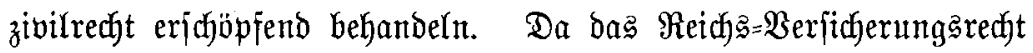

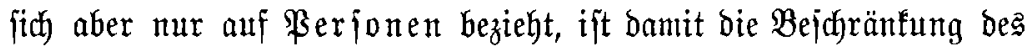

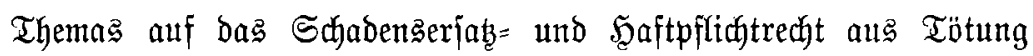
und Rörperverlebzung eines Menjuhen von jelbjt gegeben.

Übrigens mïrde auch eine Behandlung jo Keterogener Stoffe wie

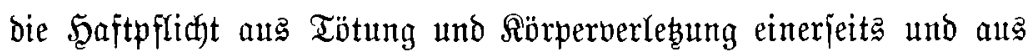
Sadjbejuäbigung andererjeits in ei nem Miserfe, abgejehen vont bem ge=

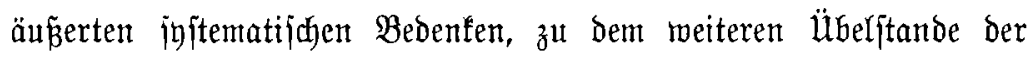

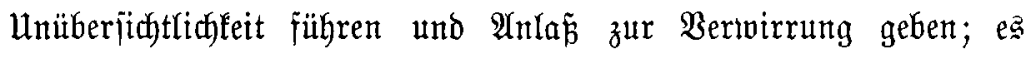

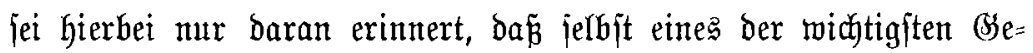

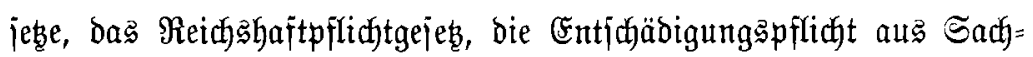
bejđäbigung nidjt regelt.

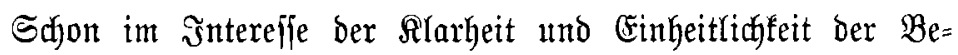


hamblung twar jomit eine Trennung ber beiden Stoffe bez̧w. Die

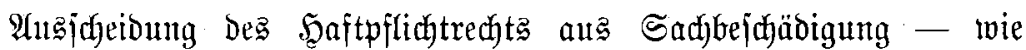
bies fdyon in ber eriten $\mathfrak{A}$ uflage ber Fall war - oringento ge $=$ boten.

So möge bent bie neue Squflage igre $\mathfrak{A}$ ufgabe erfüllen und eine ebenjo gute $\mathfrak{A}$ ufnahme finden, wie jie ber erften zut teil warb.

Berlin: Mi unden, Ende Rovember 1901.

\section{Die \$̧erfaffer.}

